\title{
Actinobacillus actinomycetemcomitans harbours type IV secretion system genes on a plasmid and in the chromosome
}

\author{
Karen F. Novak, ${ }^{1}$ Bryan Dougherty ${ }^{2}$ and Manuel Peláez ${ }^{2}$ \\ Author for correspondence: Karen F. Novak. Tel: +1 859323 8705. Fax: +1 8592576566. \\ e-mail:knova2@pop.uky.ed
}

1 University of Kentucky, College of Dentistry, Center for Oral Health Research, Lexington, KY 40536-0297, USA

2 Department of Periodontics, University of Pittsburgh School of Dental Medicine, Pittsburgh, PA 15261, USA

\begin{abstract}
Nine contiguous genes encoding a potential type IV secretion system have been identified in the chromosome of Actinobacillus actinomycetemcomitans strain VT747 and on a plasmid (pVT745) in strain VT745. Seven of these genes encode predicted proteins that share significant homology with type IV secretion proteins in Bordetella pertussis (ptl operon), Brucella melitensis biovar suis and Agrobacterium tumefaciens (virB operons), where they are involved in protein secretion, pathogen intracellular survival and multiplication, and DNA transport, respectively. Results of previous studies have demonstrated that pVT745 is a conjugative plasmid and that a secondary plasmid, pMMB67, can be mobilized from strain VT745. Given these results, it was hypothesized that (1) the type IV secretion genes on pVT745 are responsible for these two functions and (2) the type IV VT747 chromosomal genes also play a role in the transport of DNA. Wild-type and mutant strains of VT745 were evaluated for their conjugative abilities. Wild-type mating efficiency was $10^{-6}$ transconjugants per donor, while the mutant strain yielded no transconjugants. Wild-type VT745 harbouring a co-resident plasmid, pMMB67, mobilized pMMB67 at a frequency of $10^{-6}$, while VT747 was unable to mobilize this plasmid. These results support the hypothesis that the plasmidencoded type IV secretion system on pVT745 is involved in DNA transport. However, the chromosomally encoded secretion system may not play a role in DNA transport in strain VT747. While the precise function of these chromosomal genes in strain VT747 has not been determined, Northern blot analyses demonstrated that these genes are expressed in both Act. actinomycetemcomitans strains VT745 and VT747.
\end{abstract}

Keywords: type IV secretion, bacterial secretion systems, extrachromosomal, chromosomal

\section{INTRODUCTION}

Actinobacillus actinomycetemcomitans is a Gram-negative pathogen associated with infective endocarditis (Chen et al., 1991), brain abscesses (Martin et al., 1967), prosthetic heart valve infections (Hamori \& Slama, 1989) and certain forms of periodontal disease (Moore et al., 1982; Zambon et al., 1983). A number of proposed virulence factors, many of which are either cell-surface associated or released into the extracellular environ-

The GenBank accession number for the type IV secretion genes of Act. actinomycetemcomitans reported in this paper is AF332996. ment, have been identified in Act. actinomycetemcomitans (Fives-Taylor et al., 1996). However, mechanisms by which Act. actinomycetemcomitans transports these substances from the intracellular to the extracellular environment have not been elucidated.

Type IV secretion systems have been identified in a variety of bacteria (Christie \& Vogel, 2000). Specifically, a type IV system is responsible for intracellular survival and multiplication of Bru. melitensis bv. suis (O'Callaghan et al., 1999), secretion of pertussis toxin from Bordetella pertussis (Covacci \& Rappuoli, 1993; Weiss et al., 1993) and for conjugal transport of $\mathrm{Ti}$ plasmid DNA from Agrobacterium tumefaciens to a susceptible plant (Shirasu \& Kado, 1993). The Bor. 
Table 1. Strains and plasmids used

\begin{tabular}{|c|c|c|}
\hline Strain or plasmid & Description* & Source or reference \\
\hline \multicolumn{3}{|c|}{ Act. actinomycetemcomitans strains } \\
\hline HK1651 & Genome sequencing strain & Dave Dyer, University of Oklahoma \\
\hline HK1651Rif & Rif $^{\mathrm{R}}$ & This study \\
\hline VT745 & Harbours pVT745 & LeBlanc et al. (1993) \\
\hline VT747 & Harbours type IV chromosomal genes & LeBlanc et al. (1993) \\
\hline VT705 & Does not harbour type IV genes & LeBlanc et al. (1993) \\
\hline VT748 & Does not harbour type IV genes & LeBlanc et al. (1993) \\
\hline \multicolumn{3}{|l|}{ E. coli strains } \\
\hline \multicolumn{3}{|l|}{ Plasmids } \\
\hline pVT745 & Conjugative plasmid & LeBlanc et al. (1993), Galli et al. (2001) \\
\hline pUC19 & $\mathrm{Ap}^{\mathrm{R}}$; high-copy-number cloning vector & Yannish-Perron et al. (1985) \\
\hline pKN4 & $4 \cdot 150 \mathrm{~kb}$ VT747 genomic clone & This study \\
\hline pKN12 & $4 \cdot 676 \mathrm{~kb}$ VT747 genomic clone & This study \\
\hline pKN13 & $1.577 \mathrm{~kb}$ cloned PCR product from VT747 & This study \\
\hline pKN14 & $\begin{array}{l}\mathrm{Sp}^{\mathrm{R}} \text { derivative of } \mathrm{pVT} 745 \text {; created by single cross-over into } \\
\text { 'non-essential' region }\end{array}$ & This study \\
\hline pKN15 & $\begin{array}{l}\mathrm{Sp}^{\mathrm{R}} \text { derivative of } \mathrm{pVT} 745 \text {; created by single cross-over into } \\
\text { magB03 }\end{array}$ & This study \\
\hline pMMB67 & $\mathrm{Ap}^{\mathrm{R}}$, mobilizable plasmid RSF1010 derivative & Fürste et al. (1986) \\
\hline pUS19 & $\mathrm{Sp}^{\mathrm{R}}$ derivative of $\mathrm{pUC19}$ & Benson \& Haldenwang (1993) \\
\hline
\end{tabular}

${ }^{*}$ Rif ${ }^{\mathrm{R}}$, rifampicin resistance; $A \mathrm{p}^{\mathrm{R}}$, ampicillin resistance; $S \mathrm{p}^{\mathrm{R}}$, spectinomycin resistance.

pertussis transport system is comprised of a chromosomally encoded, $9.5 \mathrm{~kb}$, nine-gene [pertussis toxin liberation $(p t l)$ ] operon (Farizo et al., 1996; Weiss et al., 1993). A search for proteins homologous to those predicted by the $p t l$ operon revealed significant homology with seven of the 11 proteins predicted by the $v$ ir $B$ operon of Agr. tumefaciens (Shirasu \& Kado, 1993; Weiss et al., 1993). Genes of both the ptl and virB operons also share homology with conjugal transfer genes of the IncN plasmid pKM101 (Pohlman et al., 1994) and the IncP plasmid RP4 (Lessl et al., 1992). Homologous genes also have been identified in Helicobacter pylori (Tummuru et al., 1995), Wolbachia spp. (Masui et al., 2000), Rickettsia prowazekii (Andersson et al., 1998) and Legionella pneumophila (Vogel et al., 1998; Segal et al., 1999). It is proposed that each of these diverse systems is involved in the secretion of macromolecules from bacteria (Weiss et al., 1993; Christie \& Vogel, 2000) and that they may share a common ancestry (Pohlman et al., 1994; Winans et al., 1996).

Several contiguous genes encoding a potential type IV secretion system have also been identified in Act. actinomycetemcomitans. However this pathogen appears unique in that the proposed system is found on a plasmid (pVT745) in one strain (VT745) (Galli et al., 2001), while being present on the chromosome of a different strain (VT747). To our knowledge, this is the first report of a single pathogen harbouring this proposed system in both of these locations. While the plasmid-encoded system appears to be involved in conjugal transfer of pVT745 (Galli et al., 2001), the precise function of the chromosomal genes has not yet been identified. However, it is hypothesized that Act. actinomycetemcomitans may have uniquely adapted this macromolecular transport system to serve dual functions: 1) for conjugation of pVT745 in strain VT745 and 2) for macromolecular transport in strains harbouring the chromosomal genes, exemplified by VT747.

\section{METHODS}

Bacterial strains, plasmids and growth conditions. Strains and plasmids used in this study are listed in Table 1. Act. actinomycetemcomitans strains were grown in media composed of Tryptic Soy Broth supplemented with $0.6 \%$ yeast extract (TSBYE broth), and containing bacitracin and vancomycin at 75 and $5 \mu \mathrm{g} \mathrm{ml}^{-1}$, respectively (TSBYEBV; Slots, 1982). Incubation was at $37^{\circ} \mathrm{C}$ in the presence of $10 \% \mathrm{CO}_{2}$. Solid media contained $1.5 \%$ Bacto agar. The Act. actinomycetemcomitans recipient strain, HK1651Rif, was isolated as a spontaneous rifampicin-resistant mutant of strain HK1651. Transconjugants were selected on solid media containing appropriate antibiotics (spectinomycin, $100 \mu \mathrm{g} \mathrm{ml}^{-1}$; ampicillin, $25 \mu \mathrm{g} \mathrm{ml}^{-1}$; rifampicin, $50 \mu \mathrm{g} \mathrm{ml}^{-1}$ ).

Frozen competent cultures of Act. actinomycetemcomitans were prepared as previously described by Sreenivasan et al. (1991). Act. actinomycetemcomitans transformants were grown on solid TSBYE plates containing spectinomycin or ampicillin. Frozen competent cultures of Escherichia coli strain JM109 were prepared as described in Sambrook et al. (1989). E. coli JM109 transformants screened for the presence of Act. actinomycetemcomitans cloned DNA were grown at 
(a) pVT475

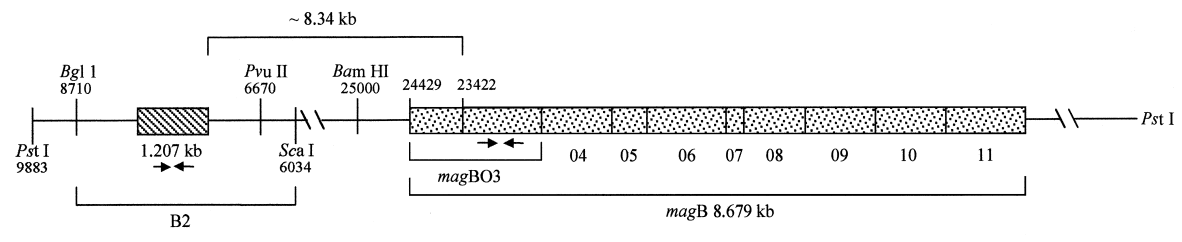

(b) VT747

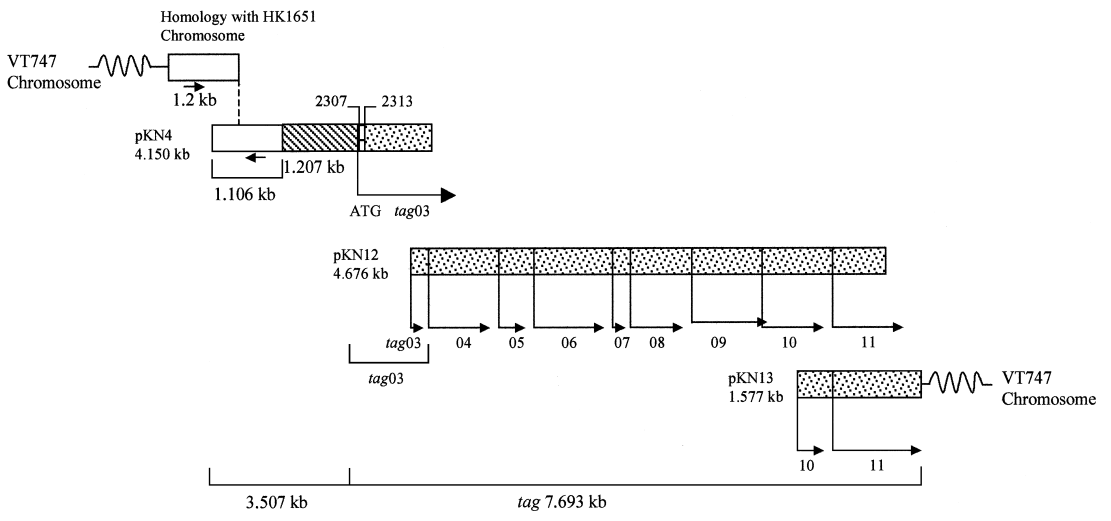

Fig. 1. Schematic representation of regions of homology shared between pVT745 and the VT747 chromosome. (a) Linearized plasmid pVT745. The schematic representation shows plasmid pVT745 linearized at the Pstl site located at $9.883 \mathrm{~kb}$ on the circular map. Other restriction sites and genes are drawn in the anticlockwise direction, consistent with transcription of the magB genes. 'B2' indicates one subcloned segment of pVT745 used in sequencing the plasmid that did not encode genes involved in replication or conjugation ('non-essential' region of the plasmid; Galli et al., 2001). The hatched box delineates the $1.207 \mathrm{~kb}$ area of this region that is also present in the VT747 chromosome. The location of PCR primers used to amplify the $1.056 \mathrm{~kb}$ internal segment of this region (as described in Methods) are indicated with converging arrows. The $8.34 \mathrm{~kb}$ region of pVT745 that may have been deleted from the VT747 chromosome is noted above the line drawing. The magB03-11 genes are indicated by the dot-filled boxes. The location of PCR primers used to amplify the $1.0 \mathrm{~kb}$ internal region of magB03 (as described in Methods) are indicated with converging arrows. (b) VT747 chromosomal DNA. White boxes represent the VT747 chromosome $5^{\prime}$ to areas of homology shared between pVT745 and VT747. The location of PCR primers used to amplify a region of VT747 chromosomal DNA located $5^{\prime}$ to pKN4 insert DNA is indicated with converging arrows. The hatched box represents the $1.207 \mathrm{~kb}$ area of homology shared between pVT745 and VT747. The seven base pairs at the end of this sequence that overlap with tag03, including the start codon of tag03, are indicated by the numbers 2307 and 2313. Dot-filled boxes represent the arrangement of the tag genes in the genomic clones, pKN4 and pKN12, and PCR product, pKN13, obtained from Act. actinomycetemcomitans strain VT747.

$37^{\circ} \mathrm{C}$ on solid YT medium (Miller, 1972) containing ampicillin or spectinomycin $\left(100 \mu \mathrm{g} \mathrm{ml}^{-1}\right)$.

DNA techniques. Genomic and plasmid DNA were isolated from Act. actinomycetemcomitans cultures by the method of Anderson \& McKay (1983) with modifications as described by LeBlanc et al. (1993). Caesium chloride/ethidium bromide density-gradient centrifugation (Sambrook et al., 1989; Beckman VTi65 rotor, 65000 r.p.m., 4 h, $20^{\circ} \mathrm{C}$ ) was used to further purify plasmids from strain VT745. E. coli transformants were screened for the presence of plasmid DNA by the alkaline lysis method of Birnboim \& Doly (1979) with modifications as described in Sambrook et al. (1989). Plasmid DNA was purified from transformants using the QIAprep Midi kit (Qiagen).

DNA was digested with restriction endonucleases as recommended by the manufacturer (Life Technologies). DNA fragments were purified from agarose gels using the Elu-Quik gel extraction kit (Schleicher and Schuell). ${ }^{32} \mathrm{P}$ labelling of DNA fragments was accomplished using a random priming kit (Life Technologies). DNA-DNA hybridization conditions have been previously described (Novak \& LeBlanc, 1994)

A genomic DNA library was constructed from Act. actinomycetemcomitans strain VT747 by ligating 3-5 kb fragments obtained from a Sau3A partial digestion into the vector pUC19 (Life Technologies) (Sambrook et al., 1989). Transformation by electroporation was used to introduce this construct into E. coli JM109 (Life Technologies). Colony lifts (Sambrook et al., 1989), probed with ${ }^{32}$ P-labelled fragments of pVT745, were performed to identify clones harbouring DNA homologous to selected regions of pVT745. The nucleotide sequences of identified clones were determined by automated DNA sequencing using the method of Sanger et al. (1977) at the University of Pittsburgh School of Medicine Biomedical Research Support Facilities. Computer analyses of the sequences were performed using MacDNASIS (Hitachi Software Engineering America). DNA and predicted protein sequences were searched against the current NCBI and GenBank databases (National Library of Medicine).

PCR (Mullis et al., 1986), using a forward primer based on the insert DNA sequence of pKN12 (Fig. 1) and a reverse primer based on the $3^{\prime}$ sequence of magB11 (Galli et al., 2001), was used to amplify a segment of chromosomal DNA from VT747 encoding partial ORFs for Tag10 and Tag11. PCR also was used to amplify two regions of pVT745 - a $1.0 \mathrm{~kb}$ internal segment of magB03 (Galli et al., 2001; Fig. 1) and a $1.056 \mathrm{~kb}$ internal region from a 'non-essential' area of the plasmid (Galli et al., 2001; Fig. 1) - and a $1.2 \mathrm{~kb}$ segment of VT747 
chromosomal DNA $5^{\prime}$ to the shared areas of homology (Fig. 1). PCR was performed in a Perkin Elmer GeneAmp PCR System 2400 using the PCR Reagent System (Life Technologies) under the following profile: 25 cycles of $30 \mathrm{~s}$ at $95^{\circ} \mathrm{C}, 30 \mathrm{~s}$ at $55^{\circ} \mathrm{C}$ and $1 \mathrm{~min}$ at $72^{\circ} \mathrm{C}$. The resulting PCR products were cloned using the Original TA Cloning Kit (Invitrogen) and their nucleotide sequences determined as described above.

Construction of recombinant derivatives of pVT745. Homologous recombination was used to introduce the selectable spectinomycin-resistance marker (LeBlanc et al., 1991) into two separate regions of pVT745. The first had been previously identified as a 'non-essential' area of pVT745, i.e. it did not harbour genes involved in either replication or conjugation functions of pVT745 (Fig. 1-B2; Galli et al., 2001). The second was into magB03 (Fig. 1), which encodes a protein homologous with PtlC and VirB4 of Bor. pertussis and Agr. tumefaciens, respectively. The $1.0 \mathrm{~kb}$ and $1.056 \mathrm{~kb}$ PCR products described above were ligated into SmaI digested, desphosphorylated vector, pUS19 (Benson \& Haldenwang, 1993). These constructs were introduced by electroporation into E. coli JM109, with transformants selected on $100 \mu \mathrm{g}$ spectinomycin $\mathrm{ml}^{-1}$. Two resulting plasmids were used to transform Act. actinomycetemcomitans strain VT745 by electroporation. The ColE1 origin of replication on pUS19 does not support extrachromosomal replication in Act. actinomycetemcomitans (Sreenivasan et al., 1991). Therefore, only transformants that had integration of either of these constructs into pVT745 by homologous recombination were able to grow in the presence of spectinomycin. Plasmid DNA from transformants was evaluated by restriction endonuclease digestion, Southern hybridization and PCR. Results from these analyses confirmed that single crossover events had occurred into both sites of pVT745. Strains harbouring these plasmid derivatives of pVT745, pKN14 and pKN15 (Table 1) were used in conjugation experiments.

Conjugation experiments. Act. actinomycetemcomitans strain VT745 harbouring either pKN14 or pKN15 were used as donors in mating experiments, with strain HK1651Rif serving as a recipient. Donors and recipients were grown in broth to mid-exponential phase and then mixed in a ratio of $1: 10$ in a total volume of $1 \mathrm{ml}$. The mixture was centrifuged and the pelleted cells resuspended in $10 \mu \mathrm{l}$ media, spotted on a TSBYE agar plate and incubated at $37^{\circ} \mathrm{C}$ for $4 \mathrm{~h}$ in $10 \% \mathrm{CO}_{2}$. The cells were scraped off and resuspended in TSBYE. Serial dilutions were spread on TSBYE plates containing spectinomycin and rifampicin. Serial dilutions of donor cells only were also plated. All plates were incubated at $37^{\circ} \mathrm{C}$ in $10 \% \mathrm{CO}_{2}$ for $48 \mathrm{~h}$. Transfer frequencies were expressed as number of transconjugants per donor cell. Selected transconjugants were evaluated by Southern blot analysis for the presence of plasmid DNA.

Mobilization experiments. Plasmid pMMB67 was introduced by electroporation into Act. actinomycetemcomitans strain VT747 and strain VT745. Transformants were selected on ampicillin. Transformants harbouring pMMB67 (confirmed by Southern blot analyses) were used as donors in mating experiments as described above. Transconjugants were selected on agar plates containing ampicillin and rifampicin. The presence of pMMB67 was confirmed by Southern blot analysis of selected transconjugants.

RNA isolation and Northern blot hybridization. Total RNA was isolated from Act. actinomycetemcomitans cells (VT747, VT745, VT705 and VT748) grown to mid-exponential phase using TRIzol reagent as described by the manufacturer
(Molecular Research Center). Each sample was treated with DNase I and a $6 \mu \mathrm{g}$ sample subjected to electrophoresis in a denaturing $1 \cdot 2 \%$ agarose/formaldehyde gel. The RNA was transferred onto nylon membranes which were hybridized (Galli \& LeBlanc, 1995) with the insert DNA of clone pKN12 labelled with ${ }^{32} \mathrm{P}$ (Fig. 1). Either a $0 \cdot 24-9 \cdot 5 \mathrm{~kb}$ or a $0 \cdot 16-1 \cdot 77 \mathrm{~kb}$ RNA ladder (Life Technologies) was used as a size marker.

\section{RESULTS AND DISCUSSION}

pVT745 is a $25.4 \mathrm{~kb}$ plasmid harboured by Act. actinomycetemcomitans strain VT745 (LeBlanc et al., 1993). Previous results from our laboratory had demonstrated that multiple regions of pVT745 shared homology with chromosomal DNA from a number of other Act. actinomycetemcomitans strains, none of which harboured plasmid DNA (Novak \& LeBlanc, 1994). Furthermore, we previously demonstrated that these shared areas of homology did not appear to represent insertion sequence elements, transposons or bacteriophage DNA, and that the intact plasmid had not merely inserted into the chromosome of any of these strains (Novak et al., 1998). Cell passaging experiments, followed by Southern blot analyses, suggested stability of the homologous DNA both within the chromosome and on the plasmid (Novak et al., 1998).

\section{Nucleotide sequence analysis}

Nucleotide sequence analysis of pVT745 revealed the presence of eleven genes, the majority of which encode predicted proteins sharing homology with VirB proteins of Brucella spp. (magB01-11; Galli et al., 2001). Southern blot hybridizations, using ${ }^{32} \mathrm{P}$-labelled segments of pVT745 that contained these genes as probes, were performed against Act. actinomycetemcomitans strain VT747 genomic DNA. Resulting autoradiographs revealed that several of these plasmid-encoded sequences also resided in the chromosome of this strain (Novak, 1994). Screening of colonies from a genomic DNA library from strain VT747 resulted in the identification of two clones that hybridized with either the $6.9 \mathrm{~kb}$ BamHI-PstI fragment of pVT745 or the $8.2 \mathrm{~kb}$ Pst I fragment (Novak \& LeBlanc, 1994; Galli et al., 2001). Nucleotide sequence analysis of these two overlapping clones (pKN4 and pKN12, Fig. 1) revealed the presence of nine contiguous genes encoding complete or partial ORFs similar to those found on pVT745. These chromosomal genes were named transport associated genes $(t a g)$ for the homology several of the predicted proteins encoded by these genes demonstrated with type IV secretion system proteins involved in macromolecular transport. They were numbered $\operatorname{tag} 03-11$ to be consistent with numbering of the homologous $\operatorname{mag} B$ genes found on pVT745 (Galli et al., 2001). A partial ORF that shared homology with MagB11 was identified at the 3' end of pKN12. PCR using a forward primer designed from the nucleotide sequence of an internal region of tag10 and a reverse primer based on the 3 ' sequence of magB11 (internal to the stop codon), was used in an attempt to amplify and clone the remainder of the gene 
encoding the VirB11/PtlH homologue from strain VT747. Nucleotide sequence analysis of this clone (pKN13, Fig. 1) revealed an overlap and continuation of the partial ORF in pKN4, but the stop codon for tag11 still could not be identified. However, a comparison with the homologous gene on pVT745 (magB11) suggests that the nucleotide sequence would continue in the VT747 chromosome for approximately ten additional bases prior to encoding the stop codon.

An analysis of the nucleotide sequences of these regions of homology shared between pVT745 and VT747 chromosomal DNA, including intervening segments, revealed that the DNA identity ranged from 93 to $99 \%$. This high degree of identity at the DNA level suggests that this plasmid may have once inserted into the chromosome of strain VT747. This is further supported by evaluating the segment of VT747 chromosomal DNA immediately $5^{\prime}$ to tag03 (Fig. 1). This chromosomal sequence shared $98.9 \%$ homology with a $1.207 \mathrm{~kb}$ region located between the PvuII and PstI sites found in the $10.3 \mathrm{~kb}$ region of pVT745 (Novak, 1994; Galli et al., 2001; Fig. 1). Although a potential ORF is encoded in this sequence, it initiates internal to the probable chromosomal integration site for pVT745 and shows no homology with predicted proteins listed in GenBank. The final seven base pairs of this sequence overlap with tag03 and includes the start codon of tag03 (Fig. 1), suggesting that a large segment of pVT745 may have inserted into the VT747 chromosome. However, since approximately $8.3 \mathrm{~kb}$ between this shared area of homology and the first 1007 base pairs of magB03 of pVT745 are not present in the chromosomal sequence (Fig. 1), this portion of pVT745 either never inserted into, or has been deleted from, the VT747 chromosome. These results confirm our previous studies (Novak \& LeBlanc, 1994), which demonstrated that the entire, intact plasmid was not present in the VT747 chromosome.

Insertion of plasmid DNA into the chromosome and subsequent rearrangement of the inserted sequence is not an uncommon event. For example, there is substantial evidence that the chromosomally encoded vap (virulence-associated protein) $1 / 3$ gene regions in the animal pathogen Dichelobacter nodosus, evolved from the site specific integration of a native $D$. nodosus plasmid, pJIR896, into the $3^{\prime}$ end of a tRNA gene (Billington et al., 1996). Subsequent duplication/ rearrangement events have been attributed to an IS element, IS1253, found on pJIR896 (Billington et al., 1996). Although a similar insertion and subsequent duplication/rearrangement may have occurred between pVT745 and the VT747 chromosome, two major differences exist between the integration areas for pJIR896 and pVT745. First, the DNA sequence $5^{\prime}$ to the VT747 type IV genes shared no homology with tRNA genes, the proposed integration site for pJIR896. Second, neither pVT745 nor the chromosomal sequence $5^{\prime}$ to the type IV secretion system genes in VT747 harboured any DNA sequences homologous to known IS elements. Therefore, it appears that tRNA genes and IS elements may not have been involved in the insertion and rearrangement of pVT745 in the VT747 chromosome.

Four of the predicted Act. actinomycetemcomitans type IV secretion proteins (Tag03, Tag09, Tag10 and Tag11) shared homology over limited regions with cag pathogenicity island proteins of $H$. pylori (Table 2), which may encode a protein secretion system (Censini et al., 1996). Bacterial pathogenicity islands often have a different $\mathrm{G}+\mathrm{C}$ content from the rest of the bacterial genome. A comparison of both the VT745 and VT747 proposed type IV secretion system genes with the Act. actinomycetemcomitans HK1651 database (University of Oklahoma; www.genome.ou.edu/act.html) showed that the $\mathrm{G}+\mathrm{C}$ content of the type IV secretion system genes was approximately $40 \mathrm{~mol} \%$ compared with $44 \mathrm{~mol} \%$ in the overall Act. actinomycetemcomitans genome. This revealed one similar characteristic shared between pathogenicity islands and the Act. actinomycetemcomitans type IV genes. Other characteristics of pathogenicity islands may also include the presence of flanking and direct repeats and IS elements, origins of plasmid replication, and genes encoding mobility elements such as integrases and transposases (Hou, 1999). Because these mobility elements are active, many pathogenicity islands are unstable, excising from the genome at frequencies of $10^{-4}$. Pathogenicity islands also are frequently associated with tRNA genes, which serve as proposed recombination sites (Hou, 1999). As previously stated, the DNA sequence $5^{\prime}$ to the VT747 chromosomal type IV secretion system genes shares no homology with tRNA genes and there is no evidence for IS or other mobile genetic elements in either the pVT745 or the VT747 sequence. In addition, our previous studies have demonstrated that the type IV secretion system genes are stably maintained in the VT747 chromosome and on pVT745 (Novak et al., 1998). Therefore, many of the characteristic features of previously identified pathogenicity islands do not appear to exist in this region of the VT747 chromosome or on pVT745. However, the nucleotide sequence of VT747 chromosomal DNA 3' to tag11 is currently unknown. This sequence may contain DNA homologous to mobility elements, and/or areas of direct or inverted repeats when compared with the $5^{\prime}$ sequence. Future experiments are designed to identify and determine the nucleotide sequence of this $3^{\prime}$ region in an attempt to characterize the chromosomal integration site.

Although the chromosomal and plasmid sequences share significant homology, specific differences are noted when comparing the plasmid-encoded type IV genes with those located on the chromosome. First, the VT747 chromosome does not harbour a gene encoding a VirB1 homologue, as seen on pVT745 (magB01; Galli et al., 2001). The Bor. pertussis ptl system also does not harbour a virB1 homologue (Weiss et al., 1993; Christie \& Vogel, 2000) and VirB1 has been shown to be dispensable for plant tumourigenesis in Agr. tumefaciens (Berger \& Christie, 1994). Second, while the predicted sizes of the homologues encoded by Act. actinomycetemcomitans pVT745 and the VT747 chromosome 
Table 2. Comparison of selected type IV secretion system predicted proteins to Act. actinomycetemcomitans VT747

All columns are arranged as follows: predicted protein designation (top row); no. amino acids in predicted protein (middle row); percentage identity/similarity with Act. actinomycetemcomitans VT747 type IV secretion system genes (bottom row). ND, Not done; NI, none identified (no homologous protein from this bacterium identified in the GenBank database). The accession numbers for the sequences reported here are Act. actinomycetemcomitans VT747, AF332996; Act. actinomycetemcomitans VT745, AF302424; Bru. melitensis biovar suis, AF141604; Agr. tumefaciens, AB01180 and AF242881; Bor. pertussis, L10720; H. pylori, AF282853, AE001481.

\begin{tabular}{|c|c|c|c|c|c|c|c|c|c|}
\hline \multirow[t]{3}{*}{ Act. actinomycetemcomitans VT747 } & Tag03 & Tag04 & Tag05 & Tag06 & Tag07 & Tag08 & Tag09 & Tag10 & Tag11 \\
\hline & 589 & 243 & 75 & 333 & 47 & 228 & 289 & 369 & 340 \\
\hline & ND & ND & ND & ND & ND & ND & ND & ND & ND \\
\hline \multirow[t]{3}{*}{ Act. actinomycetemcomitans VT745 } & MagB03 & MagB04 & MagB05 & MagB06 & MagB07 & MagB08 & MagB09 & MagB10 & MagB11 \\
\hline & 923 & 258 & 75 & 333 & 47 & 228 & 289 & 369 & 343 \\
\hline & $97 / 98$ & $96 / 98$ & $100 / 100$ & $87 / 87$ & $93 / 93$ & $96 / 96$ & $99 / 99$ & $97 / 98$ & $99 / 99$ \\
\hline \multirow[t]{3}{*}{ Bru. melitensis biovar suis } & VirB4 & VirB5 & NI & VirB6 & NI & VirB8 & VirB9 & VirB10 & VirB11 \\
\hline & 832 & 238 & - & 347 & - & 239 & 289 & 391 & 397 \\
\hline & $42 / 62$ & $20 / 44$ & - & $20 / 39$ & - & $37 / 57$ & $36 / 52$ & $37 / 56$ & $55 / 67$ \\
\hline \multirow[t]{3}{*}{ Agr. tumefaciens } & VirB4 & $\mathrm{NI}$ & NI & $\mathrm{NI}$ & NI & VirB8 & VirB9 & VirB10 & VirB11 \\
\hline & 789 & - & - & - & - & 237 & 293 & 377 & 343 \\
\hline & $31 / 50$ & - & - & - & - & $25 / 46$ & $22 / 35$ & $42 / 64$ & $34 / 52$ \\
\hline \multirow[t]{3}{*}{ Bor. pertussis } & PtlC & NI & NI & NI & NI & PtlE & PtlF & PtlG & PtlH \\
\hline & 824 & - & - & - & - & 276 & 273 & 336 & 339 \\
\hline & $41 / 60$ & - & - & - & - & $31 / 55$ & $33 / 48$ & $33 / 48$ & $40 / 60$ \\
\hline \multirow[t]{3}{*}{ H. pylori } & CagE & NI & NI & NI & NI & $\mathrm{NI}$ & $\begin{array}{l}\text { Cag } \\
\text { protein }\end{array}$ & $\begin{array}{l}\text { Cag } \\
\text { protein }\end{array}$ & $\begin{array}{l}\text { Cag } \\
\text { protein }\end{array}$ \\
\hline & 981 & - & - & - & - & - & 522 & 1819 & 330 \\
\hline & $30 / 50$ & - & - & - & - & - & $29 / 51$ & $30 / 53$ & $37 / 55$ \\
\hline
\end{tabular}

were generally very similar, a notable exception was MagB03 and Tag03 (PtlC/VirB4 homologues). The predicted MagB03 protein encoded by pVT745 is 923 aa, compared to 589 aa for the VT747-encoded Tag03. A comparison of this predicted homologue in other bacteria (Table 2) revealed a size of 832 aa in Bru. suis (O'Callaghan et al., 1999), 789 aa in Agr. tumefaciens (Shirasu et al., 1990), 824 a in Bor. pertussis (Weiss et al., 1993) and 981 aa in H. pylori (Censini et al., 1996). Although variability in the sizes of these proteins occurs, the pVT745-encoded protein is 334 aa larger at the amino terminus than the VT747 chromosomally encoded protein. The potential functional significance of this difference is discussed later. Finally, the VT747 chromosome did not harbour contiguous genes encoding homologues to MagB12-14 (Galli et al., 2001). Since these predicted proteins do not share homology with any of those encoded by the $p t l$ or virB operons, their absence in the chromosome of strain VT747 was not surprising.

A common feature of these secretion systems is the presence of a protein, usually cytoplasmic, that has apparent NTPase activity which provides the energy to drive the transmembrane transport (Krause et al., 2000). These NTPases share conserved motifs, including Walker Box A, an Asp Box, Walker Box B and a His Box (Rivas et al., 1997; Krause et al., 2000). Significantly, all four of these motifs were identified in the VirB11 homologues encoded by pVT745 and VT747 (magB11 and tag11; data not shown). In addition, a potential NTP-binding site, defined by the consensus
GXXGXGKT was found in the PtlC/VirB4 homologues encoded by the chromosomal and plasmid sequences (tag03 and magB03; data not shown).

\section{Conjugation experiments}

Results of previous experiments revealed that pVT745 was a conjugative plasmid (Galli et al., 2001). The homology shared between the $\operatorname{mag} B$ predicted proteins and those encoded by type IV secretion genes suggested that the $\operatorname{mag} B$ genes were responsible for conjugation functions. Because the Agr. tumefaciens VirB4 protein is essential for $\mathrm{Ti}$ plasmid DNA transport (Berger \& Christie, 1993) we proposed that the protein encoded by magB03, a VirB4 homologue, would be essential for conjugation of pVT745. A selectable marker $\left(\mathrm{Sp}^{\mathrm{R}}\right)$ was inserted through homologous recombination into a nonessential region of pVT745 as described in Methods. Self-transfer was demonstrated in mating experiments with the recipient strain HK1651Rif, where transconjugants were obtained at a frequency of $10^{-6}$ per donor. Similar techniques were used to disrupt magB03, the virB4 homologue. No transconjugants could be detected when matings were performed with this mutant strain. Although this disruption technique could have resulted in downstream polar effects, these results suggested that magBO3 is essential for transfer of pVT745. However, these experiments, which were performed in triplicate, confirmed that pVT745 is a conjugative plasmid and support the hypothesis that $m a g B$ genes are necessary for conjugation (Galli et al., 2001). 


\section{Mobilization experiments}

Since previous experiments had demonstrated that pVT745 was capable of mobilizing a non-self-transmissible plasmid, pMMB67 (Galli et al., 2001), we hypothesized that the genes found in the chromosome of strain VT747 would serve a similar function. This would be consistent with findings in L. pneumophila where a chromosomal homologue of $\operatorname{vir} B 10, \operatorname{dot} G$, has been shown to be essential for mobilization of plasmid DNA (Vogel et al., 1998). Plasmid pMMB67 was introduced by electroporation into Act. actinomycetemcomitans strain VT745 and into strain VT747. Transformants served as donors in mating experiments with the recipient, HK1651Rif. Strain VT745 mobilized pMMB67 at a frequency of $10^{-6}$ transconjugants per donor, while no transconjugants were obtained using VT747/pMMB67 as a donor. These experiments were performed in triplicate. As stated previously, a potentially significant difference in the pVT745-encoded genes and the VT747 chromosomal genes lies in the size of the VirB4/PtlC homologue (MagB03 and Tag03). Specifically, the pVT745-encoded protein is 334 aa larger at the amino terminus than the VT747 chromosomally encoded protein. Although the results of the mobilization experiments suggested that the chromosomal type IV system may not be involved in DNA transport, it is also possible that the truncated version of tag03 may be missing sequences essential for this function. To address this, the amino-terminal sequence of magB03 will be introduced in trans to strain VT747 and the mobilization experiments repeated. This may result in identification of regions of the MagB03 protein that are essential for DNA transport.

\section{Northern blot hybridization}

Northern blot analyses were performed to determine if the $m a g B$ and $\operatorname{tag}$ genes were expressed in Act. actinomycetemcomitans strains VT745 and VT747. The in vivo transcripts of the type IV genes from these two strains, as well as VT705 and VT748 (Act. actinomycetemcomitans strains that do not harbour these genes, either on a plasmid or in the chromosome) were analysed by Northern blotting in four separate experiments. The ${ }^{32}$ P-labelled $4.676 \mathrm{~kb}$ insert of pKN12 (Fig. 1) hybridized to two major transcripts of approximately $1.8 \mathrm{~kb}$ and $1.2 \mathrm{~kb}$ in both strains (Fig. 2). Two additional transcripts visualized directly above and below the $1.8 \mathrm{~kb}$ and $1.2 \mathrm{~kb}$ bands also appeared to be present in strain VT747 (Fig. 2). These two transcripts could not be visualized in strain VT745 with a shorter exposure of the autoradiograph. Finally, strain VT745 appeared to have one large and one small transcript that may not be present in strain VT747. No hybridization was detected to total RNA isolated from strains VT705 and VT748 (Fig. 2). These results demonstrated that the type IV secretion system genes are expressed in both strains.

In Bor. pertussis, the $p t l$ operon is transcribed from the ptx (pertussis toxin) promoter as part of a $>11 \mathrm{~kb}$ mRNA (Baker et al., 1995). In Act. actinomycetem-

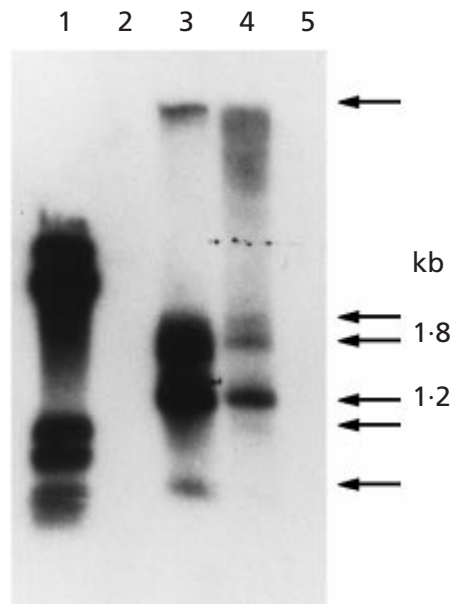

Fig. 2. Northern blot of Act. actinomycetemcomitans strains. Total RNA was isolated from Act. actinomycetemcomitans strains grown to mid-exponential phase, separated on a $1.2 \%$ agarose/formaldehyde gel and hybridized with ${ }^{32} \mathrm{P}$-labelled insert DNA from pKN12. Lanes: 1, RNA ladder; 2, VT705; 3, VT745; 4, VT747; 5, VT748. Approximate sizes of two major transcripts are indicated in the right column, as well as the location of other potential transcripts as described in Results and Discussion.

comitans strains VT745 and VT747, many of the proposed ribosome-binding sites or the initiation codons for the type IV ORFs overlap with the previous ORF, suggesting that the genes may be transcriptionally linked. Future studies, including reverse-transcriptase PCR, will be conducted to determine if these genes are transcribed as part of an operon in these Act. actinomycetemcomitans strains. In addition, it should be noted that both the $p t l$ and $\operatorname{vir} B$ operons are regulated by proteins of two-component systems. In vitro, these systems have been shown to be regulated by substances such as nicotinamide and $\mathrm{MgSO}_{4}$, phenolic compounds, acidic $\mathrm{pH}$ and monosaccharides (Heath et al., 1995). Although similar transcript sizes were found when Act. actinomycetemcomitans strains VT745 and VT747 were grown to either mid- or late-exponential phase, an extensive analysis of a variety of growth conditions was not performed. Therefore, the conditions under which the Act. actinomycetemcomitans strains were grown may not have fully simulated those required for transcriptional regulation. Those conditions may need to be identified in the future to further analyse transcription of the type IV genes in these strains.

\section{5' nucleotide sequence analysis}

The Bor. pertussis ptl genes lie directly $3^{\prime}$ from the pertussis toxin structural genes (Weiss et al., 1993). Since the exact function of the tag genes in VT747 has not been elucidated, we hypothesized that the DNA sequence $5^{\prime}$ of the tag genes could encode a protein potentially secreted by this type IV system. To address this hypothesis, we evaluated a $1 \cdot 2 \mathrm{~kb}$ DNA sequence immediately $5^{\prime}$ of the areas of homology shared between 
pVT745 and VT747 (Fig. 1) for the presence of ORFs. This was accomplished by comparing this $5^{\prime}$ sequence with the database for Act. actinomycetemcomitans strain HK1651 (University of Oklahoma; www.genome.ou.edu/act.html). A contiguous fragment was identified in the database that matched the VT747 sequence. PCR, using primers based on pVT747 sequence (reverse primer) and HK1651 sequence (forward primer), was used to amplify a $1.2 \mathrm{~kb}$ fragment of VT747 chromosomal DNA. The nucleotide sequence of this fragment shared $96 \%$ homology with a PCR product amplified from HK1651 using similar techniques. Translation of this sequence revealed the presence of an ORF sharing homology with the predicted acetohydroxyacid synthase isoenzyme of $E$. coli. This protein is involved in the biosynthesis of branched-chain amino acids (Hill et al., 1997). Any potential significance of this finding has yet to be determined.

In conclusion, genes sharing homology with those of type IV secretion systems have been identified in Act. actinomycetemcomitans. This micro-organism appears unique in that the type IV genes are located on a plasmid in one strain and on the chromosome in a different strain. While there is evidence that the plasmid-encoded genes are involved in mobilization of DNA, the function of the chromosomal genes has not yet been determined. However, Northern blot analyses revealed that the genes are expressed in both strains. Further analyses will be performed to determine if these genes are cotranscribed as part of an operon. Future studies will also be performed to determine the potential origin of these sequences shared by pVT745 and Act. actinomycetemcomitans strain VT747. In addition, the precise role of these chromosomal genes and the nature of additional DNA sequences located $5^{\prime}$ and $3^{\prime}$ to the genes, will be identified. Genetic and phenotypic characterization of wild-type and mutant VT747, as well as other Act. actinomycetemcomitans strains harbouring these genes will help in answering these questions and in determining if these genes contribute to the virulence of this micro-organism.

\section{ACKNOWLEDGEMENTS}

We thank Dr Saleem Khan for review of this manuscript. This study was supported by NIH grant R29 DE12220 to K.F.N.

\section{REFERENCES}

Anderson, D. G. \& McKay, L. L. (1983). Simple and rapid method for isolating large plasmid DNA from lactic streptococci. Appl Environ Microbiol 46, 549-552.

Andersson, S. G., Zomorodipour, A., Andersson, J. O. \& 7 other authors (1998). The genome sequence of Rickettsia prowazekii and the origin of mitochondria. Nature 396, 133-140.

Baker, S. M., Masi, A., Liu, D.-F., Novitsky, B. K. \& Deich, R. A. (1995). Pertussis toxin export genes are regulated by the $p t x$ promoter and may be required for efficient translation of $p t x$ mRNA in Bordetella pertussis. Infect Immun 63, 3920-3926.

Benson, A. K. \& Haldenwang, W. G. (1993). Regulation of $\sigma^{\mathrm{B}}$ levels and activity in Bacillus subtilis. J Bacteriol 175, 2347-2356.
Berger, B. R. \& Christie, P. C. (1993). The Agrobacterium tumefaciens virB4 gene product is an essential virulence protein requiring an intact nucleoside triphosphate-binding domain. $J$ Bacteriol 175, 1723-1734.

Berger, B. R. \& Christie, P. C. (1994). Genetic complementation analysis of the Agrobacterium tumefaciens virB operon: virB2 through virB11 are essential virulence genes. J Bacteriol 176, 3646-3660.

Billington, S. J., Sinistaj, M., Cheetham, B. F., Ayres, A., Moses, E. K., Katz, M. E. \& Rood, J. I. (1996). Identification of native Dichelobacter nodosus plasmid and implications for the evolution of the vap regions. Gene 172, 111-116.

Birnboim, H. C. \& Doly, J. (1979). A rapid alkaline extraction procedure for screening recombinant plasmid DNA. Nucleic Acids Res 7, 1513-1532.

Censini, S., Lange, C., Xiang, Z., Crabtree, J. E., Ghiara, P., Borodovsky, M., Rappuoli, R. \& Covacci, A. (1996). cag, a pathogenicity island of Helicobacter pylori, encodes type 1specific and disease-associated virulence factors. Proc Natl Acad Sci U S A 93, 14648-14653.

Chen, Y. C., Chang, S. C., Luh, K. T. \& Hseieh, W. C. (1991). Actinobacillus actinomycetemcomitans endocarditis: a report of four cases and review of the literature. Q J Med 81, 871-878.

Christie, P. J. \& Vogel, J. P. (2000). Bacterial type IV secretion: conjugation systems adapted to deliver effector molecules to host cells. Trends Microbiol 8, 354-360.

Covacci, A. \& Rappuoli, R. (1993). Pertussis toxin export requires accessory genes located downstream from the pertussis toxin operon. Mol Microbiol 8, 429-434.

Farizo, K. M., Cafarella, T. G. \& Burns, D. L. (1996). Evidence for a ninth gene, $p t l I$, in the locus encoding the pertussis toxin secretion system of Bordetella pertussis and formation of a PtlI-PtlF complex. J Biol Chem 271, 31643-31649.

Fives-Taylor, P. D., Meyer, D. \& Mintz, K. (1996). Virulence factors of the periodontopathogen Actinobacillus actinomycetemcomitans. J Periodontol 67, 291-297.

Fürste, J. P., Pansegrau, W., Frank, R., Blöker, H., Scholz, P., Bagdasarian, M. \& Lanka, E. (1986). Molecular cloning of the plasmid RP4 primase region in a multi-host-range tacP expression vector. Gene 48, 119-131.

Galli, D. M. \& LeBlanc, D. J. (1995). Transcriptional analysis of rolling circle replicating plasmid pVT736-1: evidence for replication control by antisense RNA. J Bacteriol 177, 4474-4480.

Galli, D. M., Chen, J., Novak, K. F. \& LeBlanc, D. J. (2001). Nucleotide sequence analysis of conjugative plasmid pVT745. J Bacteriol 183, 1585-1594.

Hamori, P. J. \& Slama, T. G. (1989). Actinobacillus prosthetic valve endocarditis. Am Heart J 118, 853-854.

Heath, J. D., Charles, T. C. \& Nester, E. W. (1995). Ti plasmid and chromosomally encoded two-component systems important in plant cell transformation by Agrobacterium. In Two-Component Signal Transduction, pp. 367-392. Edited by J. A. Hoch and T. J. Silhavy. Washington, DC: American Society for Microbiology.

Hill, C. M., Pang, S. S. \& Duggleby, R. G. (1997). Purification of Escherichia coli acetohydroxyacid synthase isoenzyme II and reconstitution of active enzyme from its individual pure subunits. Biochem J 327, 891-898.

Hou, Y.-M. (1999). Transfer RNAs and pathogenicity islands. Trends Biochem Sci 24, 295-298.

Krause, S., Barcena, M., Pansegrau, W., Lurz, R., Carazo, J. M. \& Lanka, E. (2000). Sequence related protein export NTPases encoded by the conjugative transfer region of RP4 and by the $c a g$ 
pathogenicity island of Helicobacter pylori share similar hexameric ring structures. Proc Natl Acad Sci U S A 97, 3067-3072.

LeBlanc, D. J., Lee, L. N. \& Inamine, J. M. (1991). Cloning and nucleotide base sequence analysis of a spectinomycin adenyltransferase $\mathrm{AAD}(9)$ determinant from Enterococcus faecalis. Antimicrob Agents Chemother 35, 1204-1210.

LeBlanc, D. J., Lee, L. N., Abu-Al-Jaibat, A. R., Sreenivasan, P. K. \& Fives-Taylor, P. M. (1993). Identification of plasmids in Actinobacillus actinomycetemcomitans and construction of intergeneric shuttle plasmids. Oral Microbiol Immunol 8, 94-99.

Lessl, M., Balzer, D., Pansegrau, W. \& Lanka, E. (1992). Sequence similarities between the RP4 Tra2 and the Ti VirB region strongly support the conjugation model for T-DNA transfer. J Biol Chem 28, 20471-20480.

Martin, B. F., Derby, B. M., Budzilovich, G. N. \& Ransohoff, J. (1967). Brain abscess due to Actinobacillus actinomycetemcomitans. Neurology 17, 833-837.

Masui, S., Tetsuhiki, S. \& Ishikawa, H. (2000). Genes for the type IV secretion system in an intracellular symbiont, Wolbachia, a causative agent of various sexual alterations in arthropods. $J$ Bacteriol 182, 6529-6531.

Miller, J. H. (1972). Experiments in Molecular Genetics. Cold Spring Harbor, NY: Cold Spring Harbor Laboratory.

Moore, W. E. C., Holdeman, L. V., Smibert, R. M., Hash, D. E., Burmeister, J. A. \& Ranney, R. R. (1982). Bacteriology of severe periodontitis in young adults. Infect Immun 38, 1137-1148.

Mullis, K., Faloona, F., Scharf, S., Saiki, R., Horn, G. \& Erlich, H. (1986). Specific enzymatic amplification of DNA in vitro: the polymerase chain reaction. Cold Spring Harbor Symp Quant Biol 51, 263-273.

Novak, K. F. (1994). Characterization of plasmid pVT745 isolated from Actinobacillus actinomycetemcomitans. PhD thesis, University of Texas Health Science Center, San Antonio, TX, USA.

Novak, K. F. \& LeBlanc, D. J. (1994). Characterization of plasmid pVT745 isolated from Actinobacillus actinomycetemcomitans. Plasmid 31, 31-39.

Novak, K. F., Lee, L. N. \& LeBlanc, D. J. (1998). Functional analysis of pVT745, a plasmid from Actinobacillus actinomycetemcomitans. Oral Microbiol Immunol 13, 124-128.

O'Callaghan, D. O., Cazevieille, C., Allardet-Servent, A., Boschiroli, M. L., Bourg, G., Foulongne, V., Frutos, P., Kulakov, Y. \& Ramuz, M. (1999). A homologue of the Agrobacterium tumefaciens VirB and Bordetella pertussis Ptl type IV secretion systems is essential for intracellular survival of Brucella suis. Mol Microbiol 33, 1210-1220.

Pohlman, R. F., Genetti, H. D. \& Winans, S. C. (1994). Common ancestry between IncN conjugal transfer genes and macromolecular export systems of plant and animal pathogens. Mol Microbiol 14, 655-668.

Rivas, S., Bolland, S., Cabezon, E., Goni, F. M. \& de la Cruz, F. (1997). TrwD, a protein encoded by the IncW plasmid R388, displays an ATP hydrolase activity essential for bacterial conjugation. J Biol Chem 272, 25583-25590.

Sambrook, J. Fritsch, E. F. \& Maniatis, T. (1989). Molecular Cloning: a Laboratory Manual, 2nd edn. Cold Spring Harbor, NY : Cold Spring Harbor Laboratory.

Sanger, F., Nicklen, S. \& Coulson, A. R. (1977). DNA sequencing with chain-terminating inhibitors. Proc Natl Acad Sci US A 74, 5463-5467.

Segal, G., Russo, J. J. \& Shuman, H. A. (1999). Relationships between a new type IV secretion system and the $i \mathrm{~cm} /$ dot virulence system of Legionella pneumophila. Mol Microbiol 34, 799-809.

Shirasu, K. \& Kado, C. I. (1993). The virB operon of the Agrobacterium tumefaciens virulence regulon has sequence similarities to $\mathrm{B}, \mathrm{C}$, and $\mathrm{D}$ open reading frames downstream of the pertussis toxin-operon and to the DNA transfer-operons of broad-host-range conjugative plasmids. Nucleic Acids Res 21, 353-354.

Shirasu, K., Morel, P. \& Kado, C. I. (1990). Characterization of the virB operon of an Agrobacterium tumefaciens $\mathrm{Ti}$ plasmid: nucleotide sequence and protein analysis. Mol Microbiol 4, 1153-1163.

Slots, J. (1982). Selective medium for isolation of Actinobacillus actinomycetemcomitans. J Clin Periodontol 15, 606-609.

Sreenivasan, P. K., LeBlanc, D. J., Lee, L. N. \& Fives-Taylor, P. (1991). Transformation of Actinobacillus actinomycetemcomitans by electroporation, utilizing constructed shuttle plasmids. Infect Immun 59, 4621-4627.

Tummuru, M. K. R., Sharma, S. A. \& Blaser, M. J. (1995). Helicobacter pylori picB, a homologue of the Bordetella pertussis toxin secretion protein, is required for induction of IL-8 in gastric epithelial cells. Mol Microbiol 18, 867-876.

Vogel, J. P., Andrews, H. L., Wong, S. K. \& Isberg, R. R. (1998). Conjugative transfer by the virulence system of Legionella pneumophila. Science 279, 873-876.

Weiss, A. A., Johnson, F. D. \& Burns, D. L. (1993). Molecular characterization of an operon required for pertussis toxin secretion. Proc Natl Acad Sci U S A 90, 2970-2974.

Winans, S. C., Burns, D. L. \& Christie, P. J. (1996). Adaptation of a conjugal transfer system for the export of pathogenic macromolecules. Trends Microbiol 4, 64-68.

Yannish-Perron, C., Vieira, J. \& Messing, J. (1985). Improved M13 phage cloning vectors and host stains: nucleotide sequences of the M13mp18 and pUC19 vectors. Gene 33, 103-119.

Zambon, J. J., Christersson, L. A. \& Slots, J. (1983). Actinobacillus actinomycetemcomitans in human periodontal disease: prevalence in patient groups and distribution of biotypes and serotypes within families. J Periodontol 54, 707-711.

Received 8 January 2001; revised 9 May 2001; accepted 25 June 2001. 